\title{
Correction to: Stepwise strategy for monitoring toxic cyanobacterial blooms in lentic water bodies
}

\author{
Inês P. E. Macário • Bruno B. Castro • \\ Maria I. S. Nunes • Cristina Pizarro • Carla Coelho • \\ Fernando Gonçalves • Daniela R. de Figueiredo
}

Published online: 23 November 2017

C) Springer International Publishing AG, part of Springer Nature 2017

\section{Correction to: Environ Monit Assess \\ https://doi.org/10.1007/s10661-017-6292-9}

Unfortunately, the name of the third author was incorrectly captured in the published online paper.

The third author publication name should have been Maria I. S. Nunes instead of Isabel M.S. Nunes.

The corrected author name is shown above.

The online version of the original article can be found at https://doi.org/10.1007/s10661-017-6292-9

I. P. E. Macário · F. Gonçalves · D. R. de Figueiredo Department of Biology, University of Aveiro, 3810-193 Aveiro, Portugal

I. P. E. Macário $(\bowtie) \cdot$ M. I. S. Nunes · F. Gonçalves •

D. R. de Figueiredo

CESAM (Centre for Environmental and Marine Studies),

University of Aveiro, 3810-193 Aveiro, Portugal

e-mail: inesefe@ua.pt

B. B. Castro

CBMA (Centre of Molecular and Environmental Biology),

Department of Biology, University of Minho, Campus de Gualtar, 4710-057 Braga, Portugal

M. I. S. Nunes

Department of Environment and Planning, University of Aveiro, 3810-193 Aveiro, Portugal

C. Pizarro - C. Coelho

Water and Soil Unit, Environmental Health Department, National Health Institute Dr. Ricardo Jorge (INSA), 4000-055 Porto,

Portugal 